\title{
The Effects of Opening on the Structural Behavior of Masonry Wall Subjected to Compressive Loading - Strain Variation
}

\author{
Bashar S. Mohammed ${ }^{1, *}$, Badorul Hisham Abu Bakar ${ }^{2}$ and K. K. Choong ${ }^{2}$ \\ ${ }^{I}$ Civil Engineering Department, Universiti Tenaga Nasional, kM 7 Jalan Kajang-Puchong,43009 Kajang, Selangor, \\ Malaysia, \\ ${ }^{2}$ School of Civil Engineering, Universiti Sains Malaysia, Penang, Malaysia
}

\begin{abstract}
The area around openings in the form of doors, windows and opening for mechanical and electrical services in axially loaded structural masonry panels are locations of strain concentration. In order to capture the true distribution of strains in discontinuous regions such as opening, test was made to measure the surface strain variation around the opening in masonry panels subject to compressive load using uniaxial foil strain gauges. Experimental results were compared with results of finite element analysis. Measured strains near the opening boundary showed high localized strain concentration near the opening boundary, which reduce as the distance from the opening boundary increase. Analytical results were in good agreement with the experimental results, where the lowest correlation factor is 0.715 .
\end{abstract}

Key Word: Masonry, Strain measurement, Strain concentration, Foil strain gauge, Finite element analysis.

\section{INTRODUCTION}

The area around the openings in the form of doors and windows in axially loaded structural panels are the location of high stress concentration [1,2]. Therefore, tensile stresses develop in the area around the opening, particularly at the corners [3]. The presence of the opening in axially loaded masonry panel will determine the load path. The load will transfer to the lintel supports by arching or corbelling action of the wall above the opening which is causing stress concentration at the corner of the opening [4]. Also the presence of the opening in axially loaded panel encourages cracks to occur. This is due to two main reasons [5]: firstly; cracks start more readily at changes in section where the presence of the opening in a masonry wall introduces local stress concentrations which, if high, can result in initial localized failure and secondly; the opening may reduce the ability of a wall panel to span between supports. This paper reports the experimental and analytical study of strain distribution around the opening in the masonry wall subjected to axial uniform vertical compression load and the comparison of the experimental and analytical walls' results.

\section{EXPERIMENTAL WORK}

\subsection{Materials}

All materials used in the construction of the test specimens were commercially available and were typical of those commonly used in building construction.

*Address correspondence to this author at the Civil Engineering Department, Universiti Tenaga Nasional, kM 7 Jalan Kajang-Puchong, 43009 Kajang, Selangor, Malaysia; E-mail: bashar@uniten.edu.my

\subsubsection{Brick Unit}

One type of engineering bricks (SK30) was used; its dimensions and mechanical properties are given in Table $\mathbf{1}$. The brick were extruded and wire cut units.

\subsubsection{Mortar}

The mortar used in the construction of the panels was as specified in the BS 5628 [6], 1: 1/2: $41 / 2$ designation (ii) mortar. Mortar consistency test was carried out by using the dropping ball apparatus, where a consistency of approximately $10 \mathrm{~mm}$ was used. Any mortar remaining 1.5 hours after mixing was discarded and a fresh batch made. Three mortar cubes were cast from each batch of mortar. The cubes were immersed in water the day after making. On the same day as the corresponding wall tested, the mortar cubes were weighted in air and water to determine the mortar relative density and then they were crushed. A summary of the mortar cubes test results is listed in Table 2.

\subsection{Description and Fabrication of Walls}

All walls were constructed in running bond. The dimensions of the wall panels were $1700 \mathrm{~mm}$ long and $1700 \mathrm{~mm}$ high. The panels were covered with polyethylene sheet for a period of three days after construction and then left uncovered until tested ( 28 days after construction). The mortar bed joint thickness was approximately $10 \mathrm{~mm}$, where they cut flush and not tooled. All the panels were constructed by the same experienced masons. The bottom course of walls was laid in a full-bed of mortar on steel plate of suitable width and length to facilitate handling and placing of the wall panel in the loading frame. The panels' surfaces were either brushed clean and painted white for easier crack observation. Reinforced concrete lintels were used on the top of the opening in the masonry wall panel, so the brickwork above 
Table 1. Dimensions and Mechanical Properties of a Brick

\begin{tabular}{|c|c|c|c|c|c|c|c|c|}
\hline \multicolumn{2}{|c|}{ Work Size (mm) } & $\begin{array}{c}\text { Compressive } \\
\text { Strength (N/mm })\end{array}$ & $\begin{array}{c}\text { Modulus of Rupture } \\
\left(\mathbf{N} / \mathbf{m m}^{2}\right)\end{array}$ & \multicolumn{2}{c|}{ Absorption (\%) } & $\begin{array}{c}\text { Initial Rate of Suction } \\
\mathbf{K g} / \mathbf{m}^{2} / \mathbf{m i n}\end{array}$ & $\begin{array}{c}\text { Saturation } \\
\mathbf{C o e f f i c i e n t}\end{array}$ \\
\hline \hline Length & Width & Height & & & $24-\mathrm{h}$ cold & 5 -h boil & \\
\hline 215 & 102.5 & 65 & 80.7 & 12.2 & 4.5 & 7.8 & 1.2 & 0.6 \\
\hline
\end{tabular}

Table 2. Mortar Cube Properties

\begin{tabular}{|c|c|c|c|c|}
\hline \multirow[t]{2}{*}{ Panel Ref. } & \multicolumn{2}{|c|}{ Density $\left(\mathrm{kg} / \mathbf{m}^{3}\right)$} & \multicolumn{2}{|c|}{ Compressive Strength $\left(\mathrm{N} / \mathrm{mm}^{2}\right)$} \\
\hline & Mean for Panel & C.V\% & Mean for Panel & C.V\% \\
\hline $\mathrm{A} 2$ & 2086.7 & 0.43 & 9.15 & 5.03 \\
\hline A5 & 2068.8 & 0.92 & 5.35 & 4.23 \\
\hline A6 & 2112.1 & 1.98 & 6.5 & 9.76 \\
\hline B1 & 2127.8 & 0.85 & 9.75 & 24.3 \\
\hline B5 & 2092 & 0.72 & 6.83 & 0.93 \\
\hline B6 & 2070 & 0.23 & 5.82 & 3.5 \\
\hline
\end{tabular}

the lintel forms a natural arch, which can transfer load to the abutments of the opening. The lintel was built into the brickwork for a distance of $100 \mathrm{~mm}$ each side. The panel configurations and strain gauges locations are shown in Fig. (1).

\subsection{Instrumentation}

Vertical loads applied on the wall panels were measured using pressure gauge attached to the hydraulic jack. Foil strain gauges were glued to the surface of the wall specimens at every gridline A, B \& C to measure the strain (strain gauges locations on each wall panel are shown in Fig. 1). All the strain gages had a gage length of $20 \mathrm{~mm}$ to ensure localized strain measurement and were connected to a multichannel strain indicator. All strain gauges used in this study were made by kyowa Co, Ltd. The gauges had a gauge factor of $2.1 \pm 1.0 \%$ with a resistance of $120.2 \pm 0.2 \Omega$. Fig. (2) show the test set up of wall Panel B1.

After 28 days from construction the wall panels were transported to the loading frame. The top of the wall was grinded and cupped with $4 \mathrm{~mm}$ thickness of plywood and then topped with rigid loading steel beam to ensure the load distributed evenly on the top of the wall specimen. The strain gages applied as described in the previous section. The vertical load was applied using of hydraulic jack. The boundary conditions assigned to the wall panels were fully restrained (fixed end) to the base of the walls whereas the top edge left free for panels A1-A6. Fixed end support was applied to the base and top edge of panels B1-B6 as shown in Fig. (3). The load was applied in $50 \mathrm{kN}$ increment. After every load increment, time was given to record readings of strain gauges. For safety reasons, the tests were concluded at applied load of $900 \mathrm{kN}$. The crack patterns and failure modes of the tested panels are shown in Appendix $\mathbf{I}$.

\section{NUMERICAL MODELING}

The finite element analysis for the models of the 12 walls (reported in this paper) was carried out using ADINA package [7]. Masonry is anisotropic material, however, for a simplified analysis approach; the elastic properties of the material were considered elastic isotropic [8]. Due to the large number of elements and limitation of the file space, only two dimensions analysis have been carried out. The panels were analyzed and dicretised by means of number of 4-nodded isoparametric plane-stress elements having two degrees of freedom at each node. Linear analysis was carried out; the Young's modulus and the Poisson's ratio utilized in this analysis were $14845 \mathrm{~N} / \mathrm{mm}^{2}$ and 0.23 ; respectively (average of four prisms). The boundary conditions and loading were similar to that of the tested panels. 


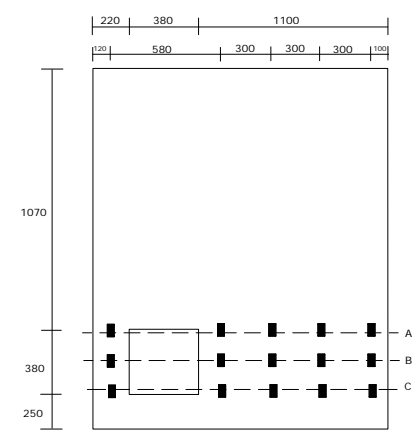

a) Panel A1 \& Panel B1

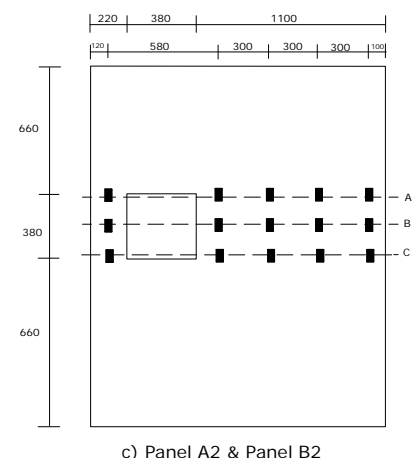

c) Panel A2 \& Panel B2

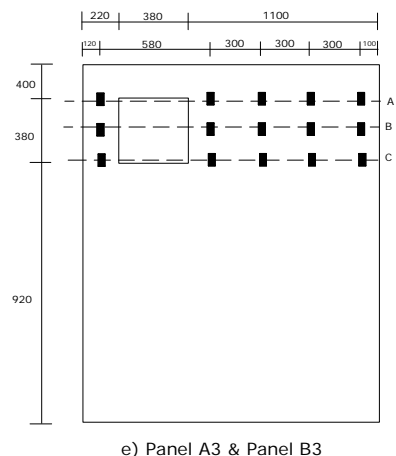

e) Panel A3 \& Panel B3

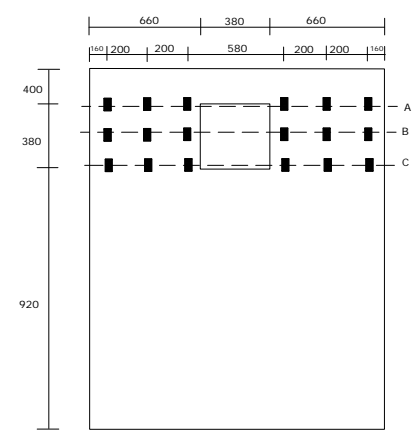

b) Panel B4 \& Panel B4

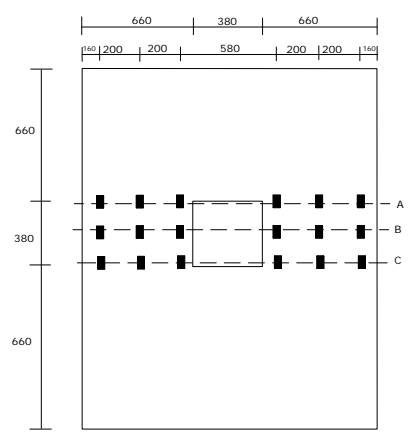

d) Panel A5 \& Panel B5

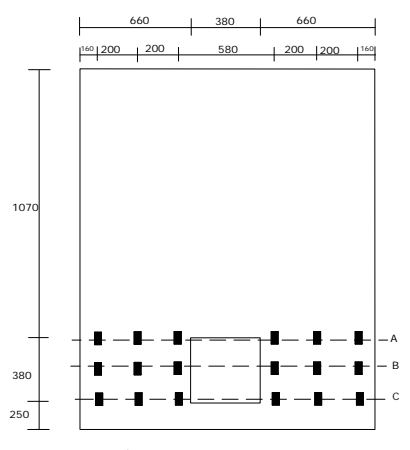

f) Panel A6 \& Panel B6

All dimenssions in $\mathrm{mm}$

Strain gauge

Fig. (1). Panel configurations and strain gauges locations.

\section{COMPARISON OF EXPERIMENTAL RESULTS WITH ANALYTICAL RESULTS}

The experimental results of strain profiles for a specific gridline (A, B, and C) for the 12 panels were compared with the analytical results as shown in Figs. (4-15). The correlation between the experimental and analytical results is assessed by means of the correlation factors as shown in Table 3 .

\section{DISCUSSION OF THE RESULTS}

High strains values were observed near the corners of the opening. However, the strains decreased with increasing distance from the opening boundary in the width direction of the panel as shown for example in Figs. (12, 13, and 14). The presence of the opening in the masonry wall caused the load path to be transferred to the lintel supports by arching or corbelling action formed above the opening. The strain profile obtained from this study can also be explained by referring to the density of the load paths. As shown in Fig. (16). The density of the load paths was getting lesser and becoming more uniform as the distance increased from the boundary of the opening in the width direction of the panel.

The comparison of the values of strain between the experimental results and finite element results was carried out by means of graphs and assessed by using correlation factor. The correlation factor indicates the extent to which the pairs of numbers for two variables lie on straight line. The correlation is con`sidered to be good for this analysis if the correlation factor is above 0.7 . The correlation factor analysis is the only statistical means available to perform the comparison presented in this paper due to the nature of data available which is not repeated.

\section{CONCLUSION}

a. The present study demonstrates that high localized strains occurred near the corners of the opening. This strain can 
be measured using foil strain gauge having small gauge length. Theses gauges gave averaged strains over small gauge length and thus they are suitable to measure the strains in the axial direction.

b. A linear finite element analysis represents particularly well the behavior of masonry wall containing opening and subjected to compressive loading; predicting successfully the localized strain concentration near the corners of the opening.

c. High-localized strain concentration is observed near the corners of the opening. This strain decreases as the distance from the opening in the width direction of the panel increases.

d. The prediction form the linear finite element analysis was reasonably in good agreement with the experimental results.

e. The different type of boundary condition assigned to the walls has insignificant effects on the strain results obtained throughout the test; this might be due to the low value of slenderness ratio, which it was equal to 15.1.

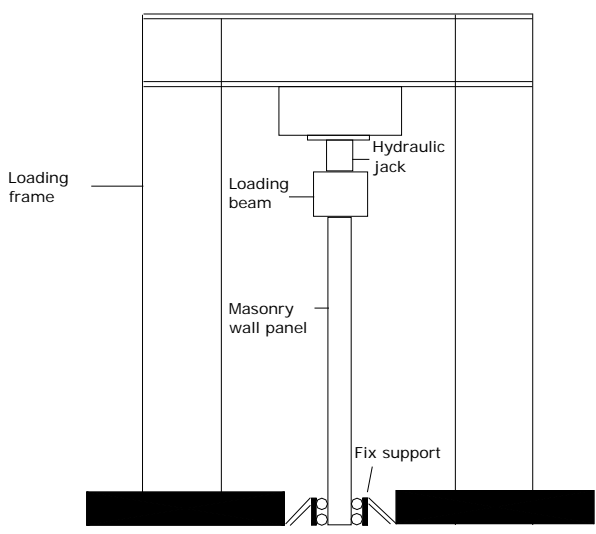

a) Test set up of panels A1-A6

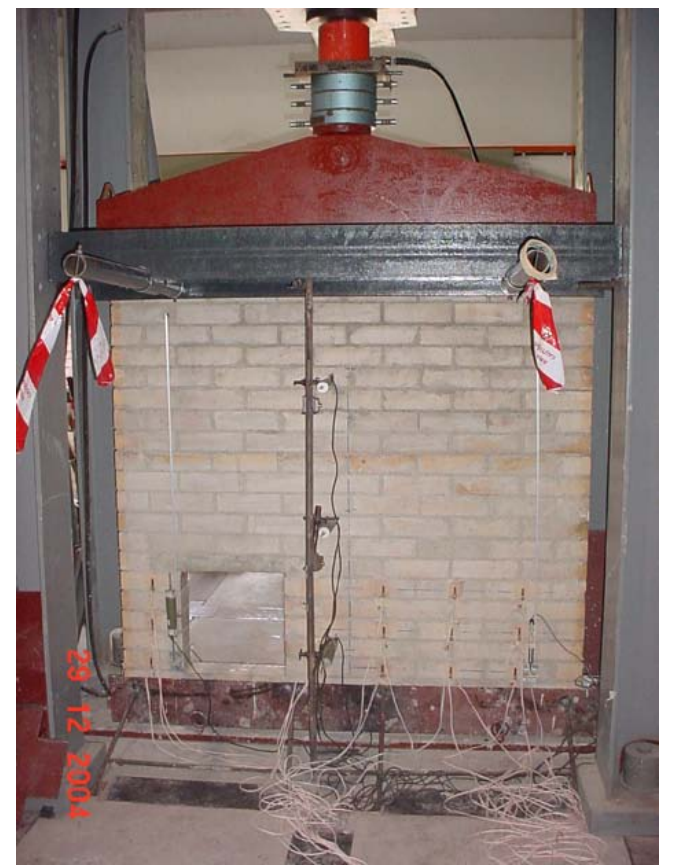

Fig. (2). Test Set up of Panel B1.

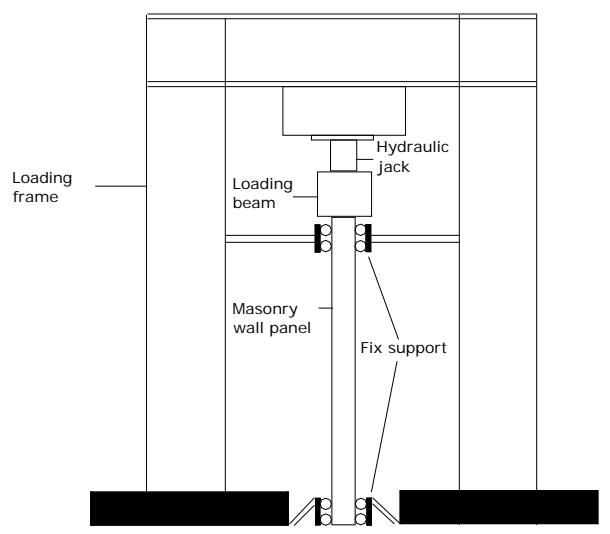

b) Test set up of panels B1- B6

Fig. (3). Boundary conditions of the Wall Panels.

Table 3. The Experimental and Analytical Correlation Factor

\begin{tabular}{|c|c|c|c|}
\hline Panel Ref. & Gridline A & Gridline B & Gridline C \\
\hline \hline A1 & 0.999 & 0.923 & 0.881 \\
\hline A2 & 0.932 & 0.97 & 0.975 \\
\hline A3 & 0.975 & 0.984 & 0.971 \\
\hline A4 & 0.927 & 0.755 & 0.866 \\
\hline A5 & 0.789 & 0.764 & 0.715 \\
\hline A6 & 0.776 & 0.941 & 0.989 \\
\hline B2 & 0.995 & 0.991 & 0.985 \\
\hline B3 & 0.96 & 0.977 & 0.983 \\
\hline B4 & 0.98 & 0.996 & 0.943 \\
\hline B5 & 0.986 & 0.988 & 0.958 \\
\hline B6 & 0.99 & 0.945 & 0.912 \\
\hline
\end{tabular}




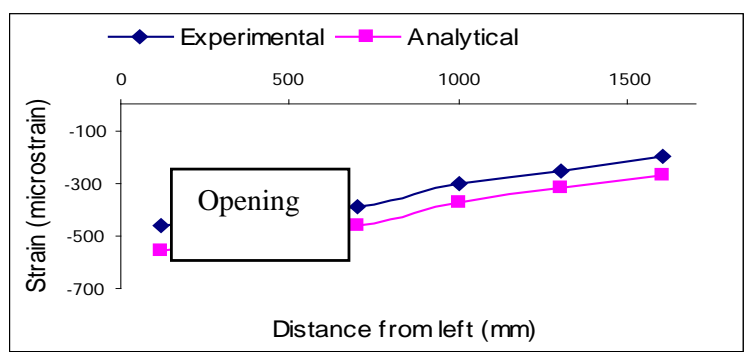

a) Gridline A

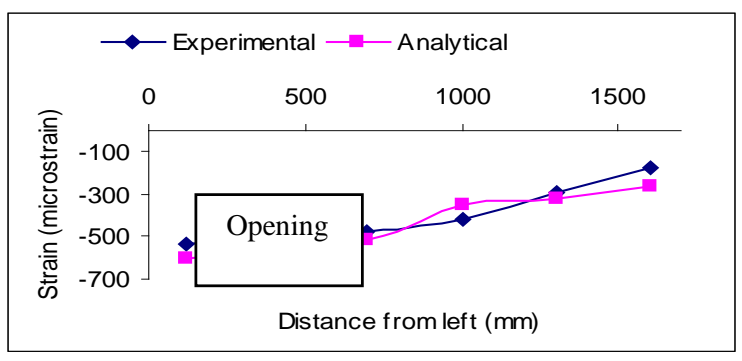

b) Gridline B

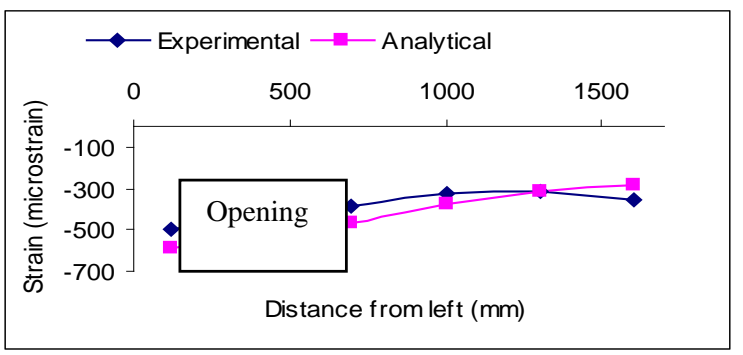

c) Gridline C

Fig. (4). Strain versus location for panel A2.

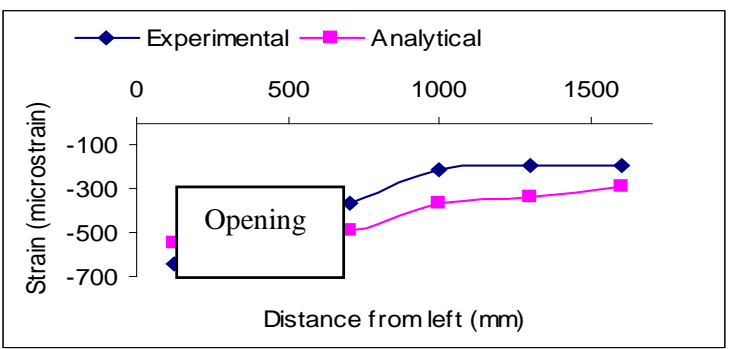

a) Gridline A

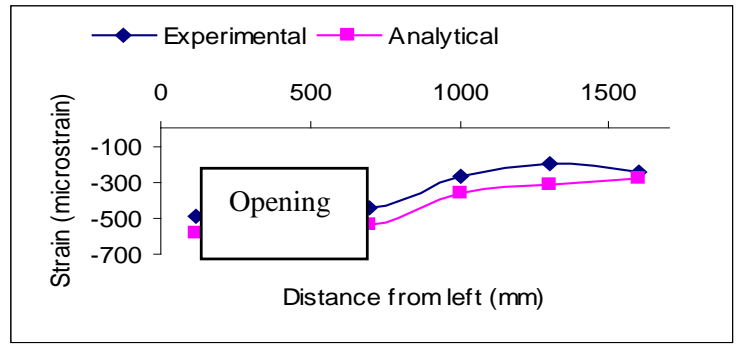

b) Gridline B

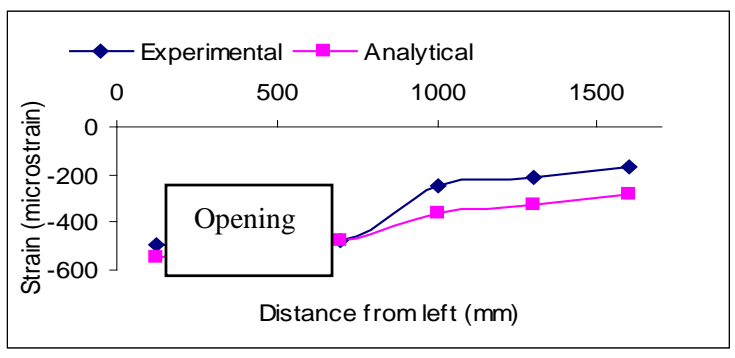

c) Gridline C

Fig. (5). Strain versus location for panel A3. 


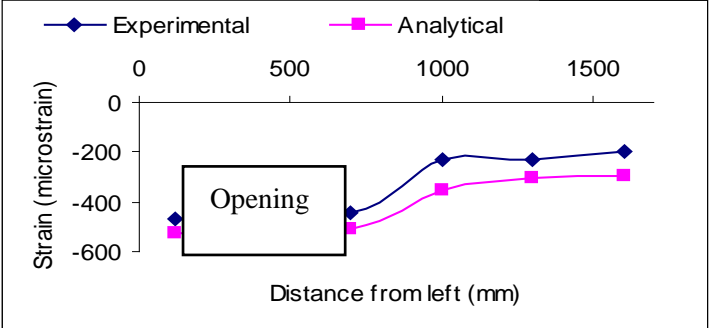

a) Gridline A

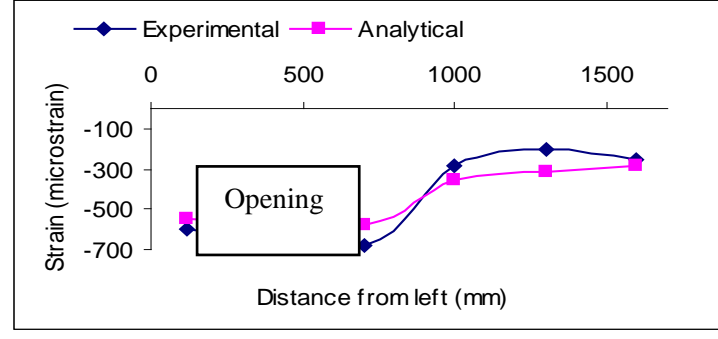

b) Gridline $B$

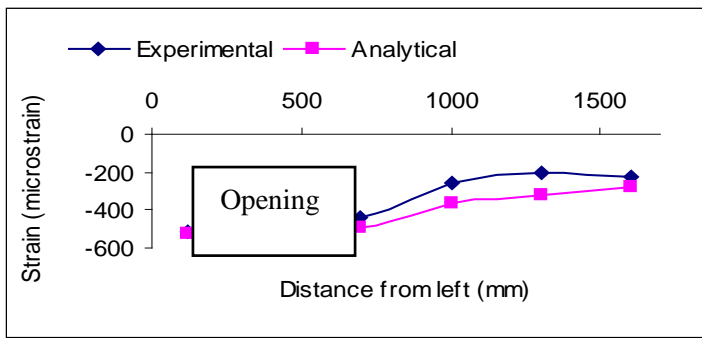

c) Gridline C

Fig. (6). Strain versus location for panel A4.

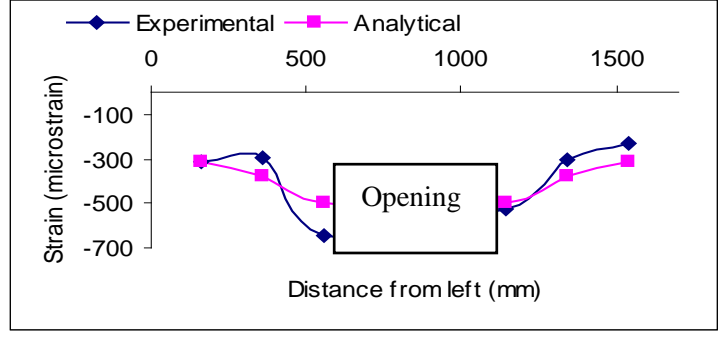

a) Gridline A

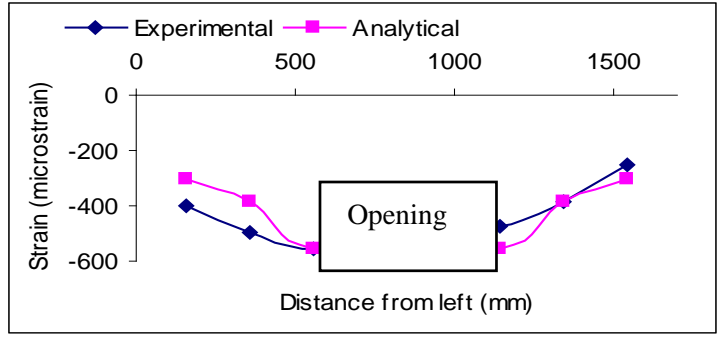

b) Gridline B

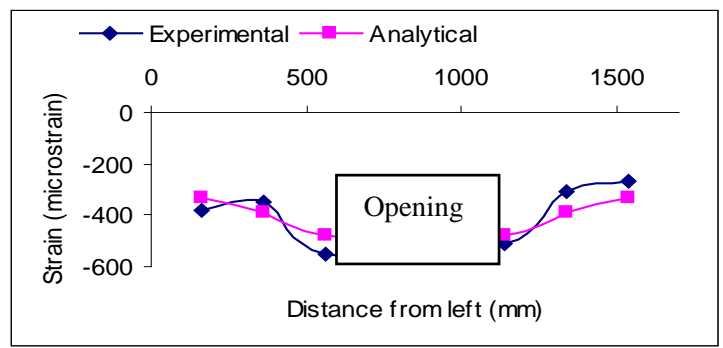

c) Gridline C

Fig. (7). Strain versus location for panel A5. 


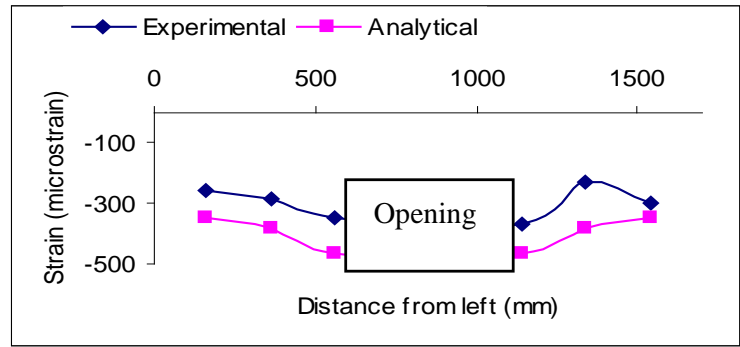

a) Gridline A

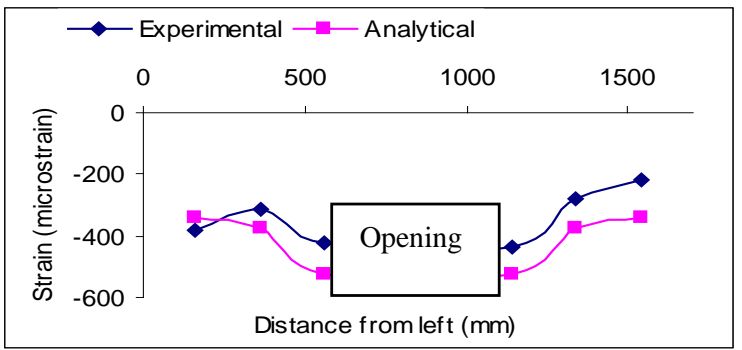

b) Gridline B

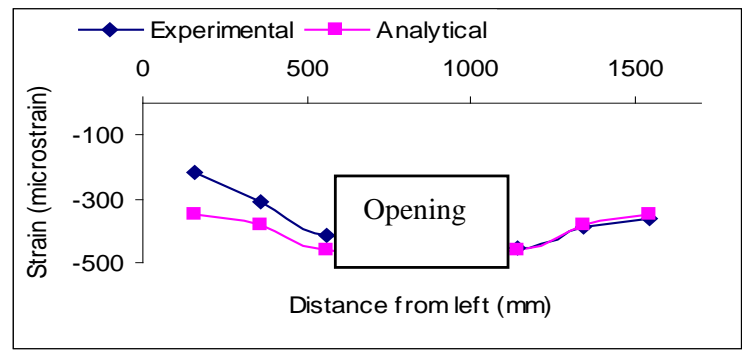

c) Gridline C

Fig. (8). Strain versus location for panel A6.

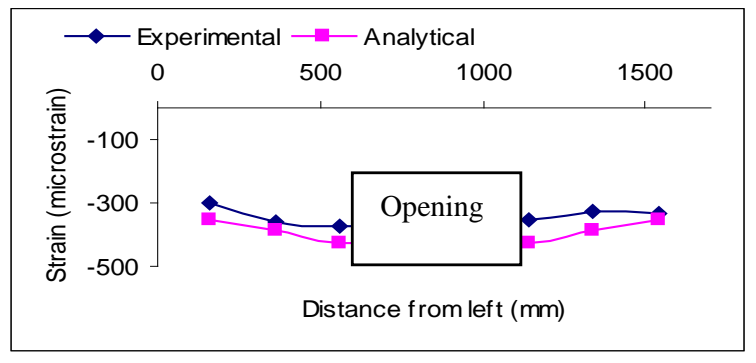

a) Gridline $A$

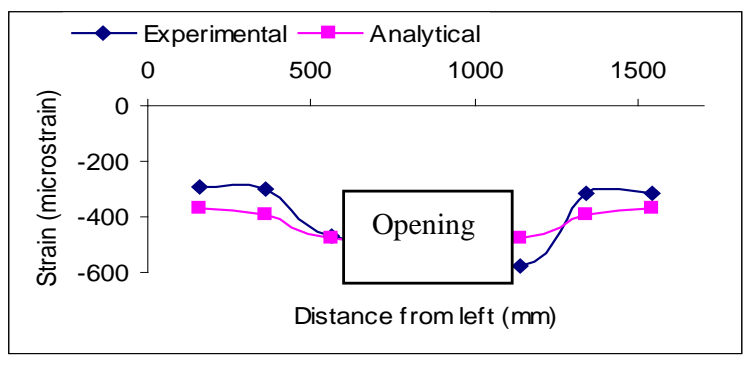

b) Gridline B

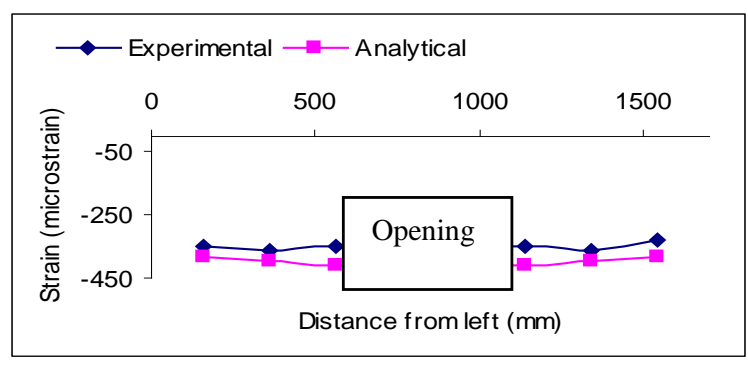

c) Gridline $C$

Fig. (9). Strain versus location for panel A7. 


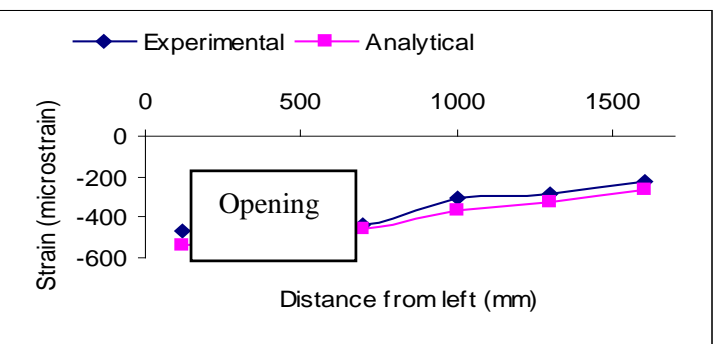

a) Gridline A

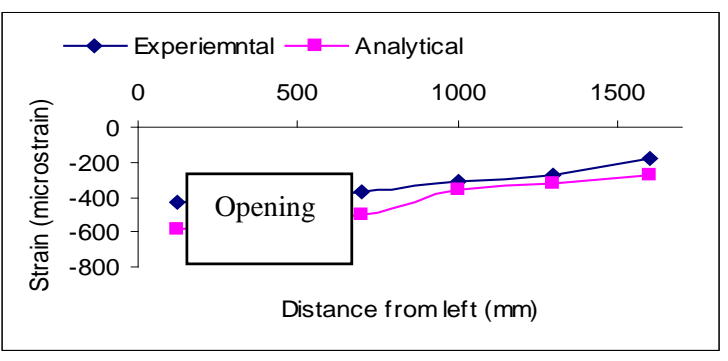

b) Gridline B

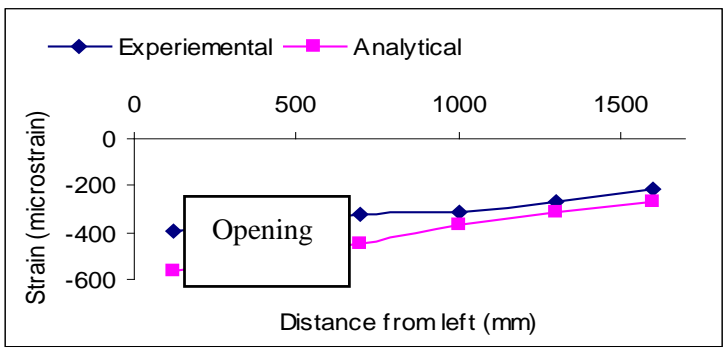

c) Gridline C

Fig. (10). Strain versus location for panel B2.

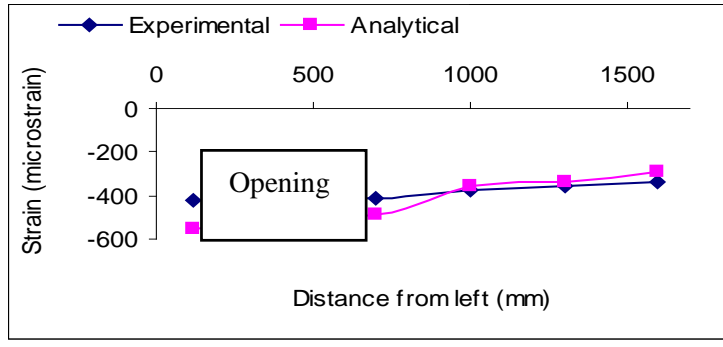

a) Gridline $A$

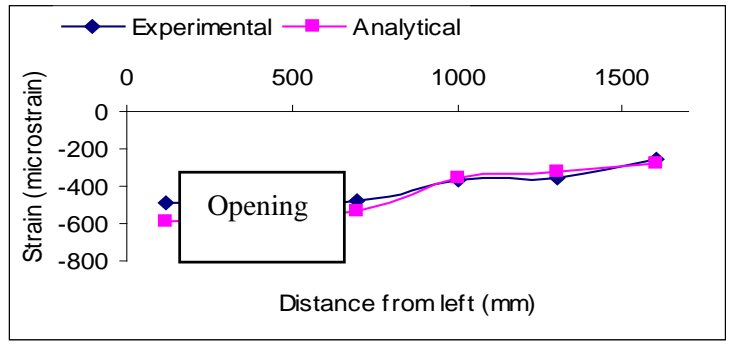

b) Gridline B

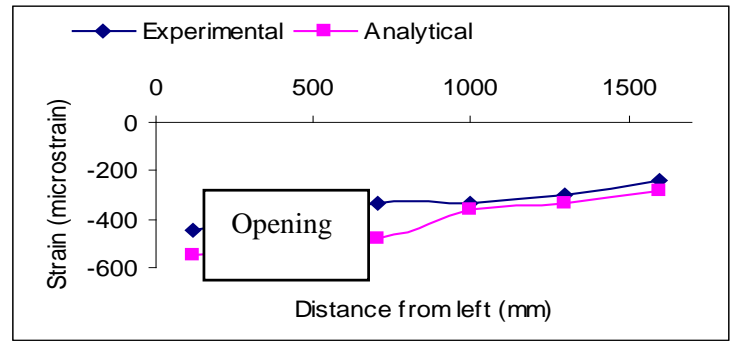

c) Gridline C

Fig. (11). Strain versus location for panel B3. 


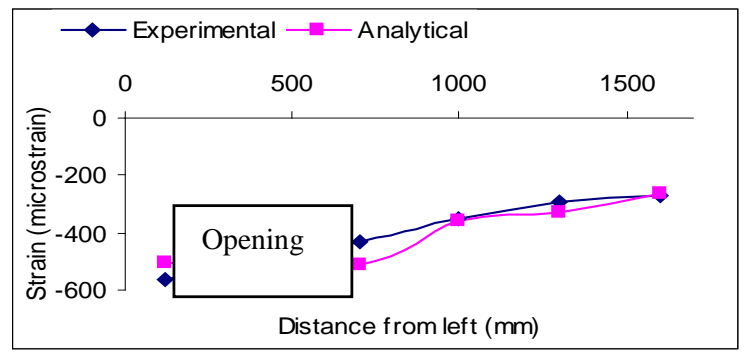

a) Gridline $\mathrm{A}$

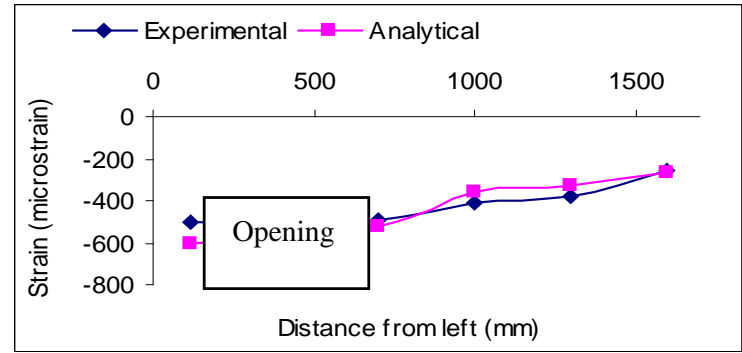

b) Gridline B

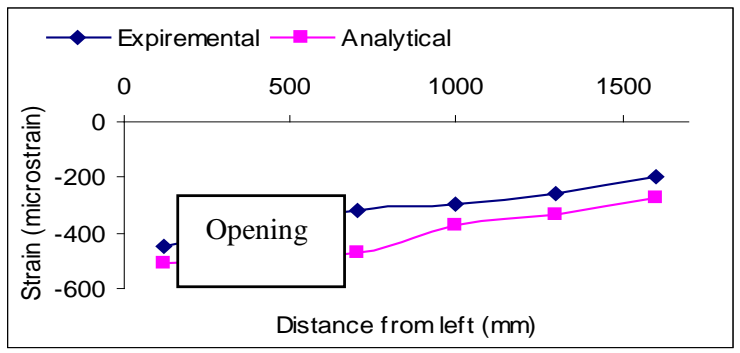

c) Gridline C

Fig. (12). Strain versus location for panel B4.

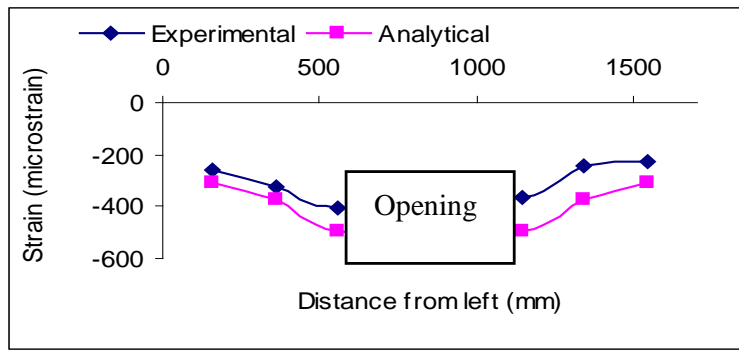

a) Gridline $\mathrm{A}$

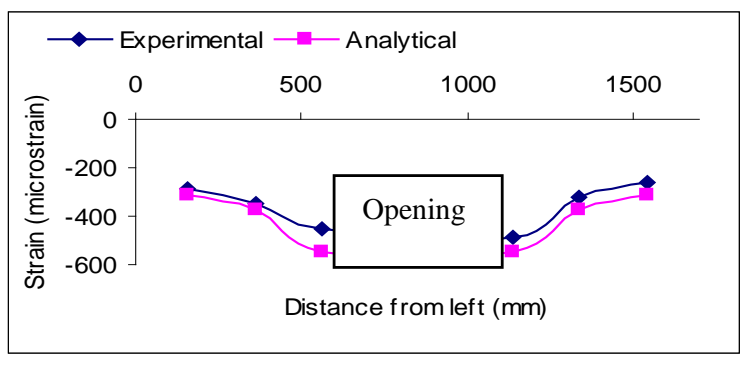

b) Gridline B

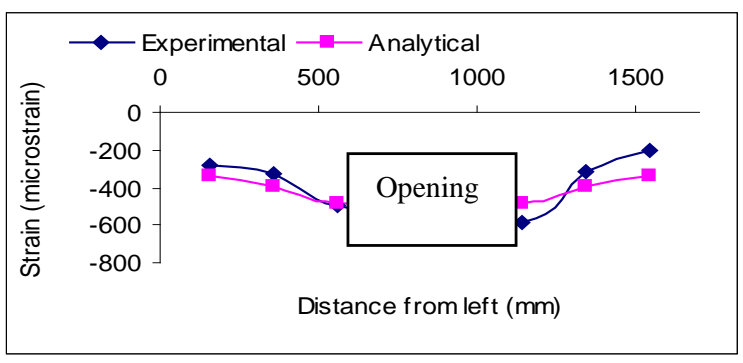

c) Gridline C

Fig. (13). Strain versus location for panel B5. 


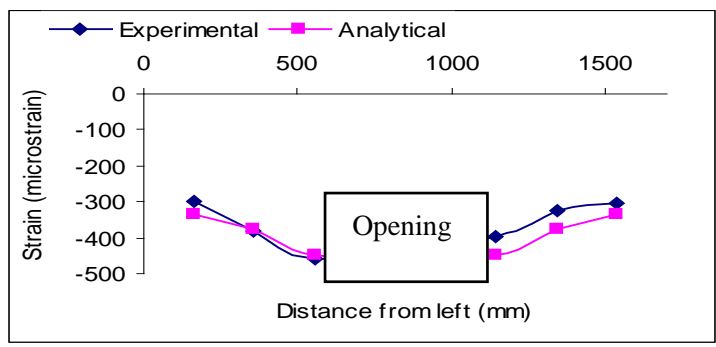

a) Gridline A

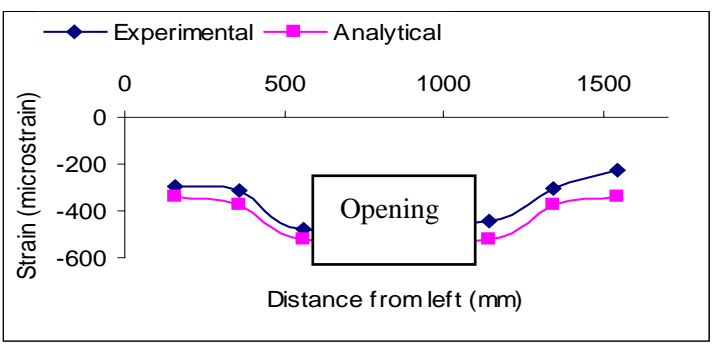

b) Gridline B

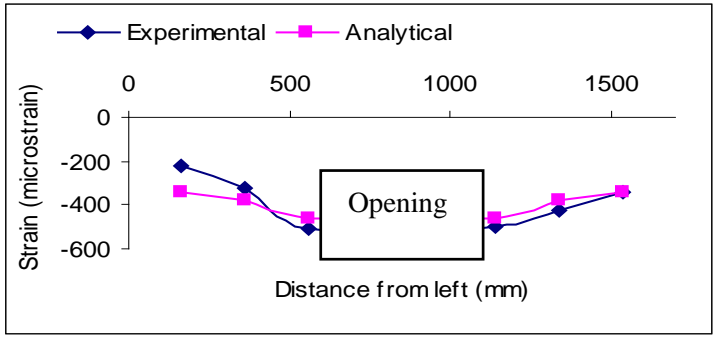

c) Gridline C

Fig. (14). Strain versus location for panel B6.

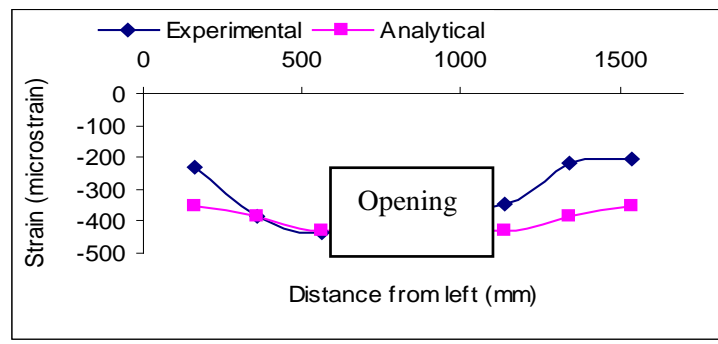

a) Gridline $A$

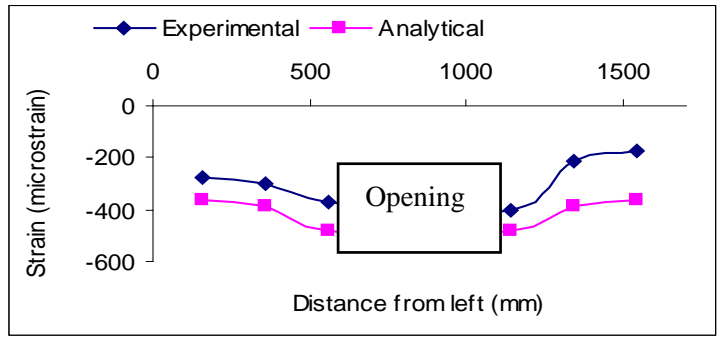

b) Gridline B

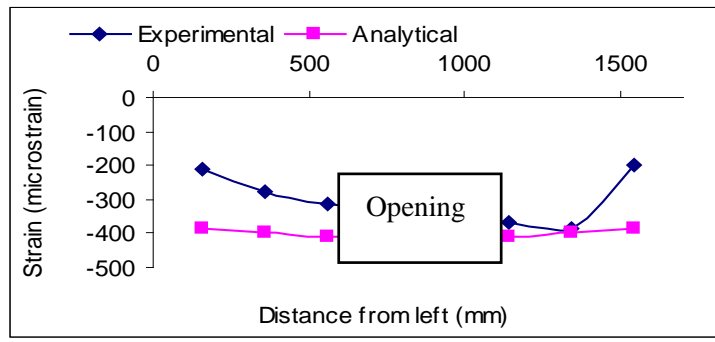

c) Gridline $C$

Fig. (15). Strain versus location for panel B7. 


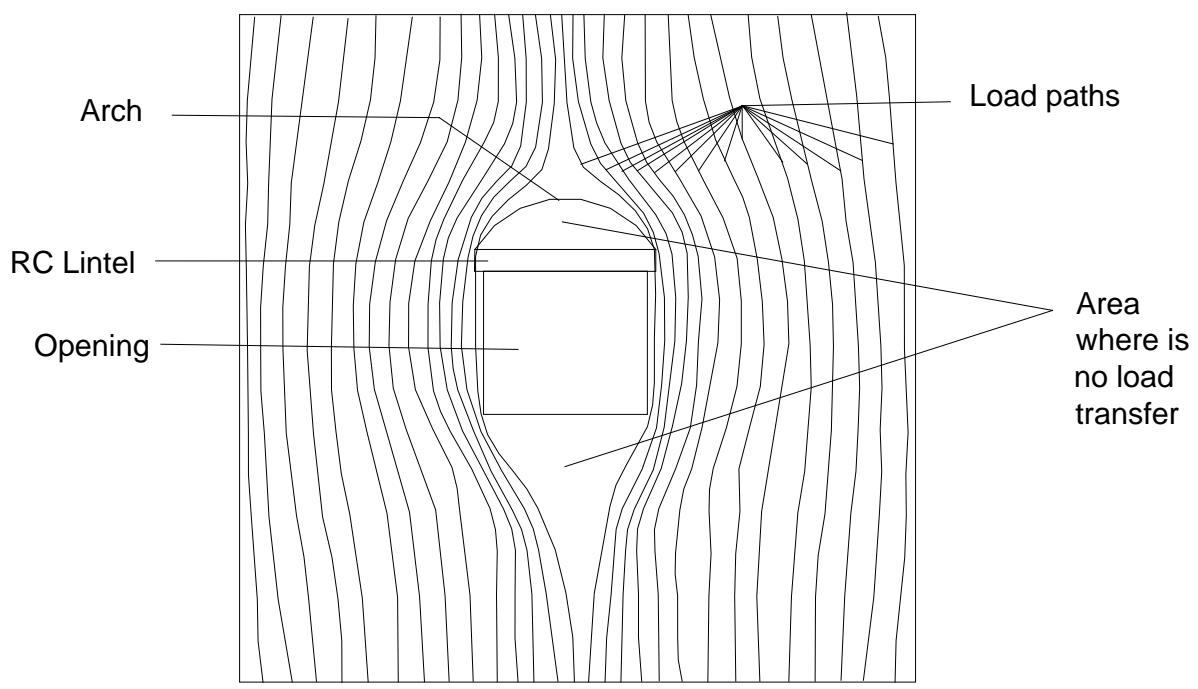

Fig. (16). The development of the load paths around the opening.

\section{APPENDIX 1}

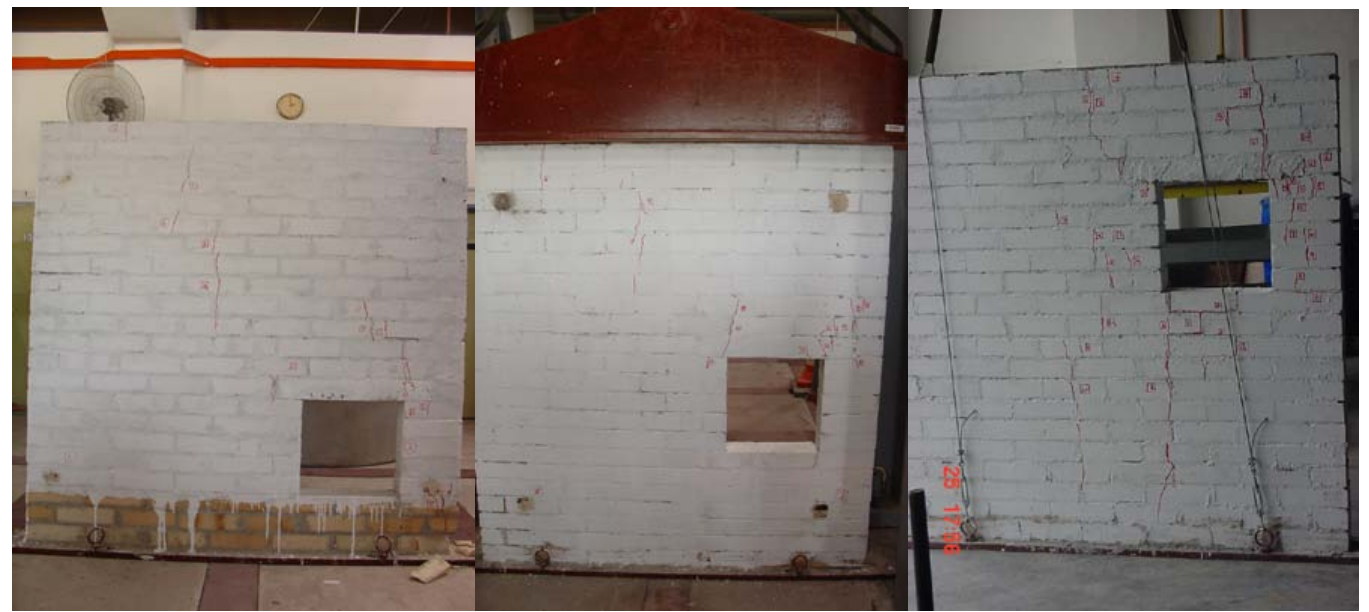

a) Panel A1

b) Panel A2

c) Panel A3

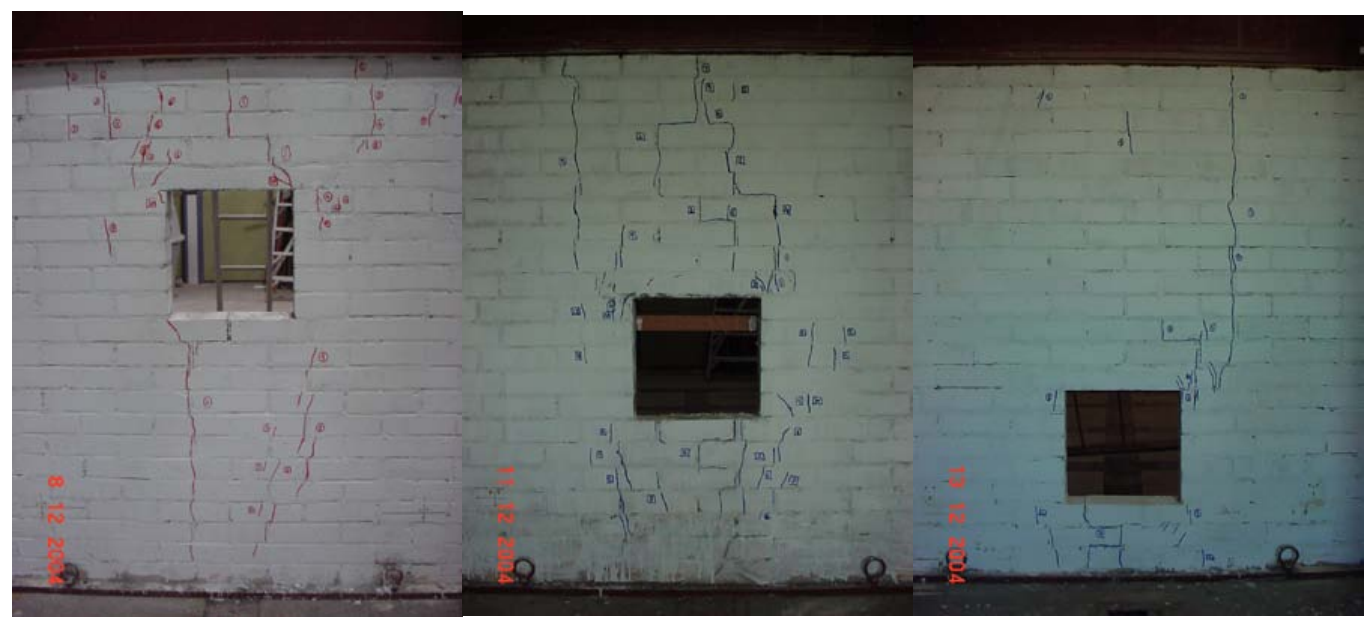

a) Panel A4

b) Panel A5

c) Panel A6

Fig. (17). Failure pattern of panels A1-A6. 


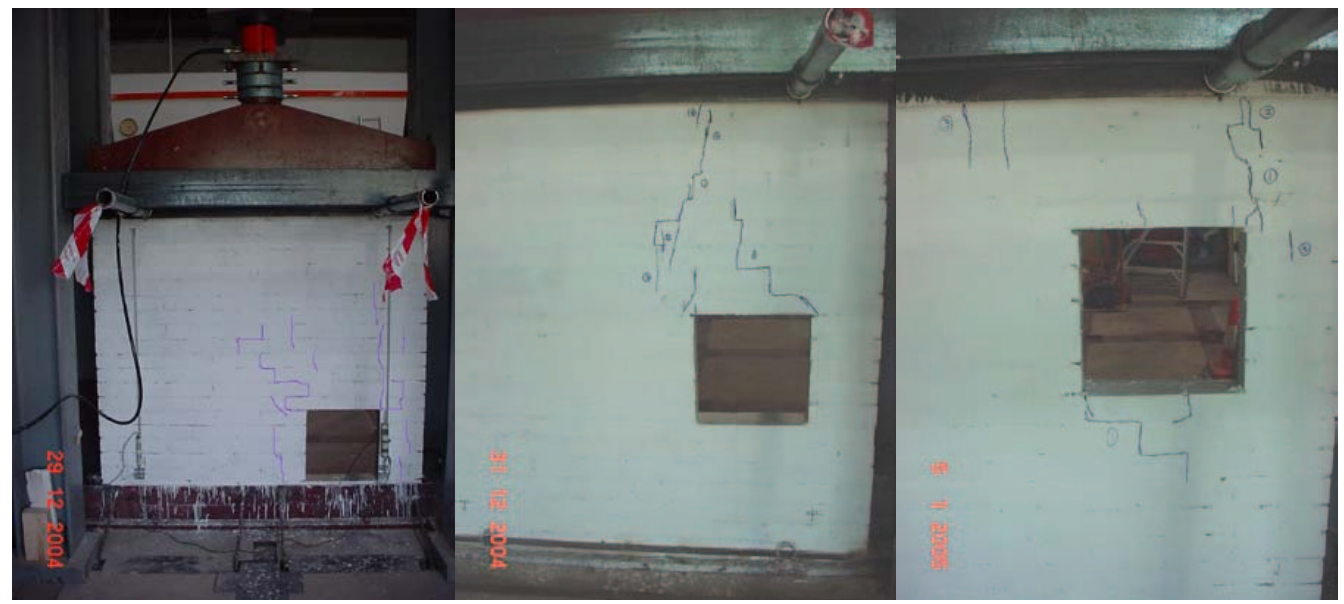

a) Panel B1

b) Panel B2

c) Panel B3

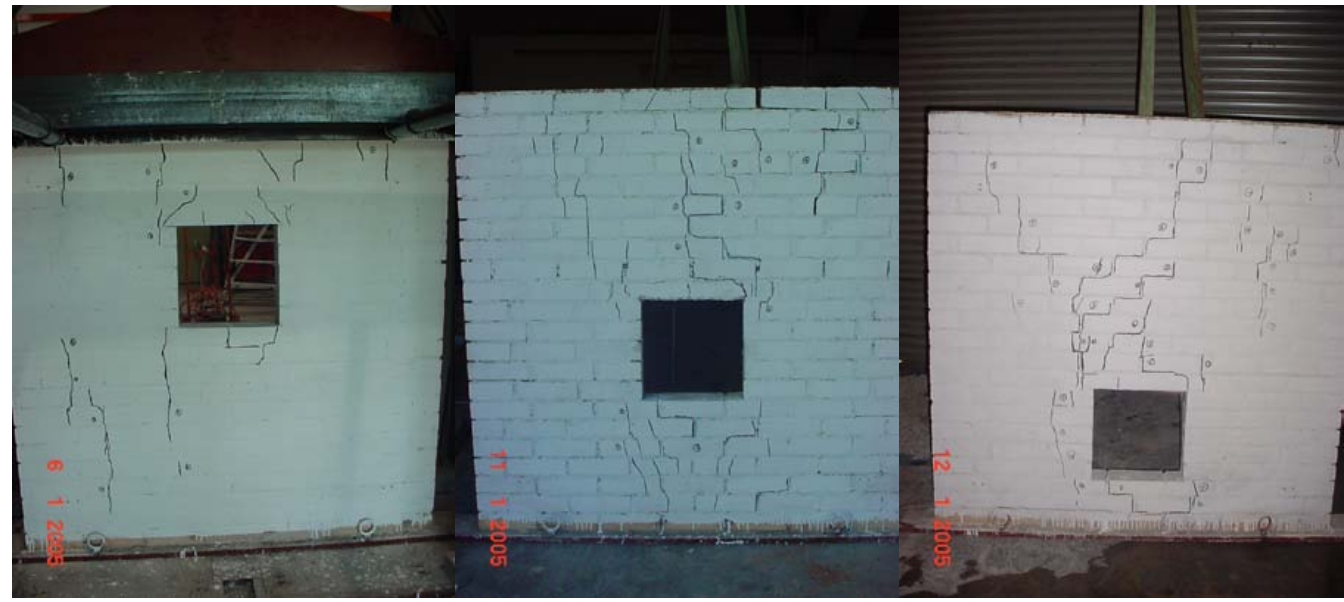

a) Panel B4

b) Panel B5

c) Panel B6

Fig. (18). Failure pattern of panels B1-B6.

\section{REFERENCES}

[1] T. P. Ganesan, P. Kalayanasudaram, and R. Ambalavanan, "Astudy of the behaviour of concrete hollow block masonry walls using a three-dimensional finite element analysis”, Journal of Masonry International, Vol. 4, No.1, pp. 31-35, 1990.

[2] A. Benayoune, A.A.A. Samad, A.A.A. Ali, and A.A. Abbasovich, "Load bearing wall panels with openings," in International Conference on Industrialized Building Systems, 2003, pp. 109-119.

[3] S. Pierruszczak, and R. Ushaksarsei, "Description of inelastic behavior of structural masonry", International Journal of Solid and Structures, Vol. 40, pp. 4003-4019, 2003.

[4] R.S. Narayanan, "Practical design of load bearing wall masonry structures" in the Symposium on the Practical Design of Masonry Structures, 1986, pp. 57-70.
[5] J. C. M. Forrest, J. Willbourne, and R. M. Kipps, "Some typical aspects of design and construction (being every day story and masonry folk!)" in the Symposium on the Practical Design of Masonry Structures, 1986, pp. 71-100.

[6] British Standard Institute, Code of Practice for Use of Masonry: Part 1. 'Structural Use of Unreinforced Masonry', London, 1992.

[7] ADINA R\&D, Inc., ADINA Users Interface Users Guide. USA, 1999.

[8] T. Yi, "Experimental Investigation and Numerical Simulation of an Unreinforced Masonry Structure with Flexible Diaphragms”, Ph.D. thesis, Georgia Institute of Technology, 2004.

(C) Mohammed et al.; Licensee Bentham Open.

This is an open access article licensed under the terms of the Creative Commons Attribution Non-Commercial License (http://creativecommons.org/licenses/by-nc/3.0/) which permits unrestricted, non-commercial use, distribution and reproduction in any medium, provided the work is properly cited. 